\title{
Modeling and Simulation Roadmap to Enhance Electrical Energy Security of U.S. Naval Bases
}

\author{
R.E. Hebner, J.D. Herbst, A.L. Gattozzi, F.M. Uriarte \\ Center for Electromechanics at The University of Texas at Austin
}

\begin{abstract}
The enhancement of the electrical energy security of Navy bases within the continental U.S. has been studied using an approach based on modeling and simulation, with the intent to achieve real time control and energy management. A notional base was developed and used for this study. Its format is general enough to be able to be used as a template for each specific Navy installation. Several preliminary simulations using commercial software have been performed on the power system of this notional base addressing a variety of operating scenarios including islanded mode and the impact of wind and solar power sources. Typical results of steady state and transient operation are also reviewed.

The results of these simulations indicate that existing software packages available today, with proper adaptations, can provide a well validated and consistent process for evaluating power system architectures and technologies and, therefore, can become a valuable tool for the implementation of the described plan for Navy bases. The study concludes giving the details of the roadmap to move forward in the process of energy security enhancement of U.S. Navy bases through modeling and simulation.
\end{abstract}

\section{INTRODUCTION}

The availability of a continuous energy supply to land-based Navy installations sufficient to carry out their appointed missions has become of critical importance as energy can no longer be seen as a commodity. As a consequence, its availability represents a significant potential vulnerability and ensuring energy security has become a mission-critical capability. Ensuring the security of energy resources and enabling continued operations of military, and possibly nearby local civilian installations in the event of a disruption of the utility supply, is a vital concern [1]. These considerations, coupled with the fact that energy installations are highly capital intensive, lead to the conclusion that investments in energy systems must be made carefully, taking into account both the present evolving energy landscape and the Navy's projected future needs. To this end, the U.S. Navy has set for itself very ambitious goals in regard to the use of renewable energy resources [2] as summarized below:

1. Derive $50 \%$ of naval land-based energy from renewable resources by 2020

2. Half of Naval bases to be net-zero to the grid by 2020

3. >20,000 smart meters among all installations

These ambitious goals dovetail very well with the stated overall DoD goal of $25 \%$ renewable energy usage by 2025. While some notable installations have already been put into service, these do not seem to be part of a systematic approach that considers the overall energy needs of the Navy; rather, they appear to have been accomplished either because of specific local circumstances (e.g., China Lake [3]), or perhaps were made in response to emerging energy policies (e.g., San Clemente [4], Coronado [5]).

Since each installation is unique, energy efficiency and security solutions will need to be developed on a caseby-case basis; however, a well validated, consistent process for evaluating power system architectures and component technologies is needed to support the development and implementation of these new concepts. There 
are also significant policy issues that will need to be addressed not only to enable the implementation of novel energy technology but also to ensure the continued availability of a sufficient energy supply.

The desired solution would have attributes that achieve the following goals:

1. Enhance the ability to fulfill the Navy's operational mission, particularly in emergency or threat conditions

2. Be cost effective to implement and improve efficiency under normal conditions

3. Reduce dependence on foreign energy resources

4. Minimize environmental impact

5. Ensure a proper level of energy security

This fifth requirement of an adequate level of energy security may not have made the list only a few years ago, but recent events have demonstrated that it is instead critical to mission success. The term "energy security" is used in this paper in the broad sense, to signify actions taken to counteract the following potential vulnerabilities:

- Insufficient energy supply (energy security in the strict sense)

- Compromise of any component of the infrastructure in the energy supply chain (physical security)

- Attack on the supervisory controls and protocols (cyber-security)

This study addresses precisely the issue of ensuring the supply of electric energy, both in the sense of energy security proper and of physical security. The issue of cyber-security is not treated per se but it will be seen that the results of this work touch upon this issue as well, at least in an indirect manner. Furthermore, this study shows that, in general, decisions made to improve energy security also may have beneficial repercussions on some of the other objectives listed above, for example, mission capability and environmental impact. Finally, this study concludes outlining a strategy for moving toward a higher level of energy security for Navy bases in the continental USA (CONUS).

\section{APPROACH}

This project investigated the feasibility of a model-based approach for the design and operation of an electricity distribution grid on a Navy base. The method summarized herein has yielded four significant benefits providing the following:

1. The information needed to operate the system most efficiently during normal operations

2. The information and control needed to reconfigure the base power system to react to the onset of emergency situations

3. The basis for assessing investments in renewable or conventional sources of power - with this model, one can plan for the multi-year evolution of a base power system balancing energy cost and energy security

4. A test-bed for enhancing cyber-physical security for the base power system in the event that the supervisory control and data acquisition (SCADA) system of the local utility is compromised.

Earlier research [6] has shown that the first two benefits are naturally coupled. A power system control approach that can reconfigure the power system for optimum mission effectiveness during an emergency can also optimize the system configuration for maximum efficiency as loads change during normal operation. This has the advantage of not being an emergency system that has to be routinely tested to ensure it is in working condition in the event of an emergency. Rather, it is used daily so there is a high level of confidence that it will be available in emergency conditions. It is also important to realize that this approach provides emergency capability well beyond what one achieves by identifying critical infrastructure and planning for its continued operation. In an extended emergency, the critical loads and operational missions change as the emergency evolves. This approach permits dynamic response to dynamic situations.

As for the assessment of investments in energy security infrastructure, it is important to note that base commanders are required to choose power sources for their bases in a rapidly changing environment. Renewable technology is changing and improving [7]. In this environment, it is important to make a consistent set of 
investments over time designed to take advantage of emerging technology while maintaining mission capability at the least cost. The model can show how today's investments can be combined with emerging technologies to provide efficiency and mission effectiveness in the future.

Finally, physical cyber-security is essential, particularly recognizing the vulnerability of supervisory control and data acquisition (SCADA) systems. Implementing a control system that can monitor the present status and at the same time evaluate with a validated model the potential options available before they are implemented (modelbased control) would provide the Navy base with a safe buffer to both external and internal cyber-threats. For example, data obtained in real time from the meters installed throughout the system could be displayed together with the results of simulations of alternative states on a shipboard energy dashboard screen, allowing the detection of unauthorized or harmful request for action. By interfacing a model-based control system with a utility SCADA system, the Navy base has added protection against intrusions through the utility systems

This work focused on developing the modeling approaches needed to assess these anticipated advantages of model-based control. The enhancement of the electrical energy security of Navy bases within the CONUS has been studied through the development of a representative notional installation based on an extensive review of naval bases. A notional base was developed to avoid highlighting the capabilities or vulnerabilities of any particular base and to provide a generic approach that can be individualized for each base. The study recognizes that the problem does not admit a general solution for all bases nor a static solution valid for a base for all time, but rather, is a continuous process that needs to be maintained and updated to face changing circumstances and challenges.

\section{DEVELOPMENT OF A NOTIONAL NAVY BASE}

To determine quantitatively the suitable level of modeling and simulation for a correct assessment of the energy security status of a U.S. Navy base and to demonstrate that the selected approach is the proper tool for the prudent upgrading of a base electric power system, a notional Navy base was developed. This was done after reviewing the wide variety of existing Navy installations in the CONUS: coastal bases, land bases, extended over a small or large area, located in all climate zones, etc. The intent was to develop a notional base that, while not aiming at duplicating the characteristics of any base in particular, incorporated the distinctive features of all in such a manner that it could function as a reference template with which one could generate significant models of actual bases by proper modification of the template parameters. Thus, it is hoped that the notional base can provide the engineering basis for a smooth transition from the technical R\&D to an effective implementation on a real facility.

The general layout of the notional base used in this study is shown in Figure 1. The general topographical sketch is a first step toward defining its details and its internal structure with an aim at determining its particular power needs which have to be known in order to develop a relevant and realistic model. For example, information about the base demographics, inventory of available resources, special loads to be supported, etc. are useful in determining the base energy and power needs. If possible, actual data should be obtained from the appointed authorities for the specific base under consideration or, if this is not practical, some estimates can be extracted on the basis of the information available when correlated with published data for typical structures and installations of the same type, even in the civilian sector. The amount and quality of information available determine the fidelity of the model. 


\section{Notional Base Layout}

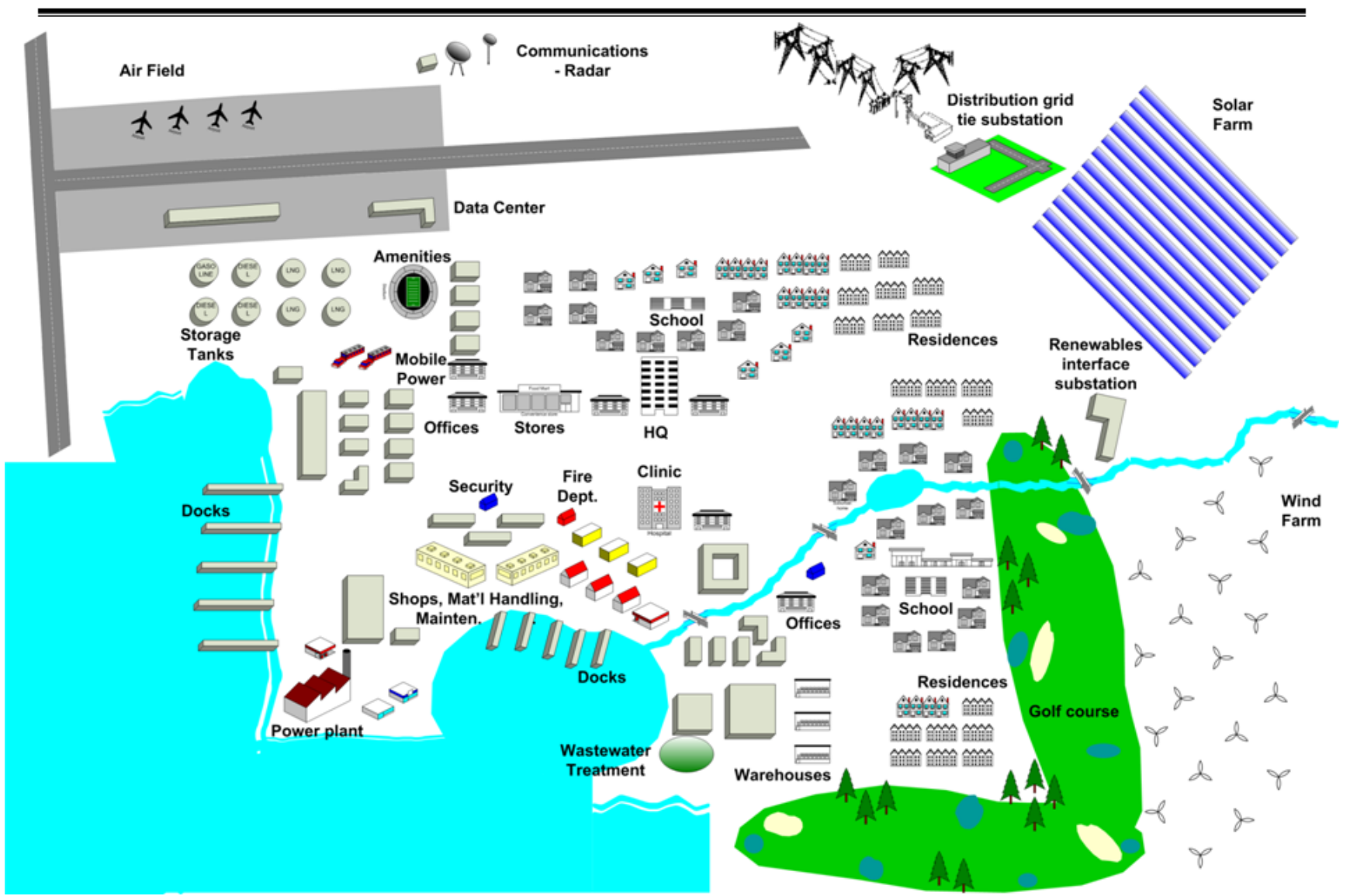

Figure 1: Topographical layout of the notional CONUS Navy base. The layout in a double circuit topology of the major distribution lines (red and blue) is also shown.

Initial processing of the data collected for the base of interest does not require specialized software: some basic macroscopic performance parameters can be generated using a simple spreadsheet, e.g. EXCEL, set up according to the general principles enunciated. As a way of example, the notional base used in this study was defined with the following characteristics:

1,000 on-base personnel:

100 officers, $75 \%$ married with family, $80 \%$ office workers

900 non-officers, $25 \%$ married with family, $40 \%$ office workers

1,000 off-base personnel:

500 office workers,

400 shop workers,

100 others

- Nominal maximum renewable power capacity: Wind 23 MW, Solar $18 \mathrm{MW}$

- Desired make-up of energy storage: $20 \%$ gasoline, 50\% diesel, $30 \%$ liquefied natural gas

- Loads are prioritized depending on their criticality.

Some assumptions had to be made to generate a working model (e.g. that a married person needs 50\% more space than a single one) but these were kept to a minimum. For the examples presented here, every effort has been made to base the spreadsheet calculations on verifiable data about residential and commercial building 
energy usage. Such information was retrieved from documentation available from the websites of the Department of Energy (DOE) [8-12], the National Renewable Energy Laboratory (NREL) [13], and other sources [14-17]. Some supplementary basic information has also been obtained from other general references. From the information database collected, estimates of the power required for the various functions can be made. For example, to estimate the average power $\mathbf{P o b}$ required in an office building, the following procedure is used:

where

$$
\text { Pob }=\operatorname{Max}\{\text { Pow } * \text { Now, Poa } * \text { Soa }\},
$$

Pow $=$ Average power per office worker $=($ MWh/worker/year $) * 1000 /[52 *($ Hours/week $)]$

Poa $=$ Average power per office unit area $=(k W h /$ unit area/year $) /[52 *($ Hours/week $)]$

Now $=$ Number of office workers (calculated based on inputs)

Soa $=$ Surface area of office (calculated based on inputs)

and where the figures for (MWh/worker/year) and ( $\mathrm{kWh} /$ unit area/year) are obtained from the sources cited previously.

Proceeding in this manner the spreadsheet estimates the following requirements for the base:

Number and types of buildings

Electric power distribution infrastructure needed

Power available from renewable energy resources

Energy storage inventory required

Total installed power capacity

Power required by the various base functions at different levels of emergency

Base survivability during emergencies

For example, the notional base described above has an energy storage inventory consisting of the following (capacities shown are per tank):

Gasoline: 1 above ground tank (500,000 gal) and 42 underground tanks (10,000 gal)

Diesel: 4 above ground tanks (500,000 gal) and 2 underground tanks (10,000 gal)

LNG: 4 above ground tanks (500,000 gal) and 9 underground tanks (10,000 gal)

Furthermore, it is estimated that the base needs $66 \mathrm{MW}$ of installed conventional power generation capacity, and it will survive for 30 days operating continuously at rated load with the available renewable and stored energy resources, given average solar irradiance and wind conditions.

If an emergency situation were to occur, the base command would respond in a manner adequate to the perceived threat. For sake of argument, beside the normal level of operation, let us define four levels of emergency for the notional base, labeled somewhat loosely in order of increasing severity as mild, severe, critical, and extreme, with no attempt to quantify them in terms of a specific numerical index. The only general expectation is that, as the severity of the emergency increases, the base command would progressively reduce the energy consumption, starting from the more discretionary loads, trying to keep the more vital loads powered as long as possible. A typical result of this exercise is a plot like the one shown in Figure 2 that shows the length of time the base is expected to be able to maintain its operations under conditions of various reductions of energy consumption. 


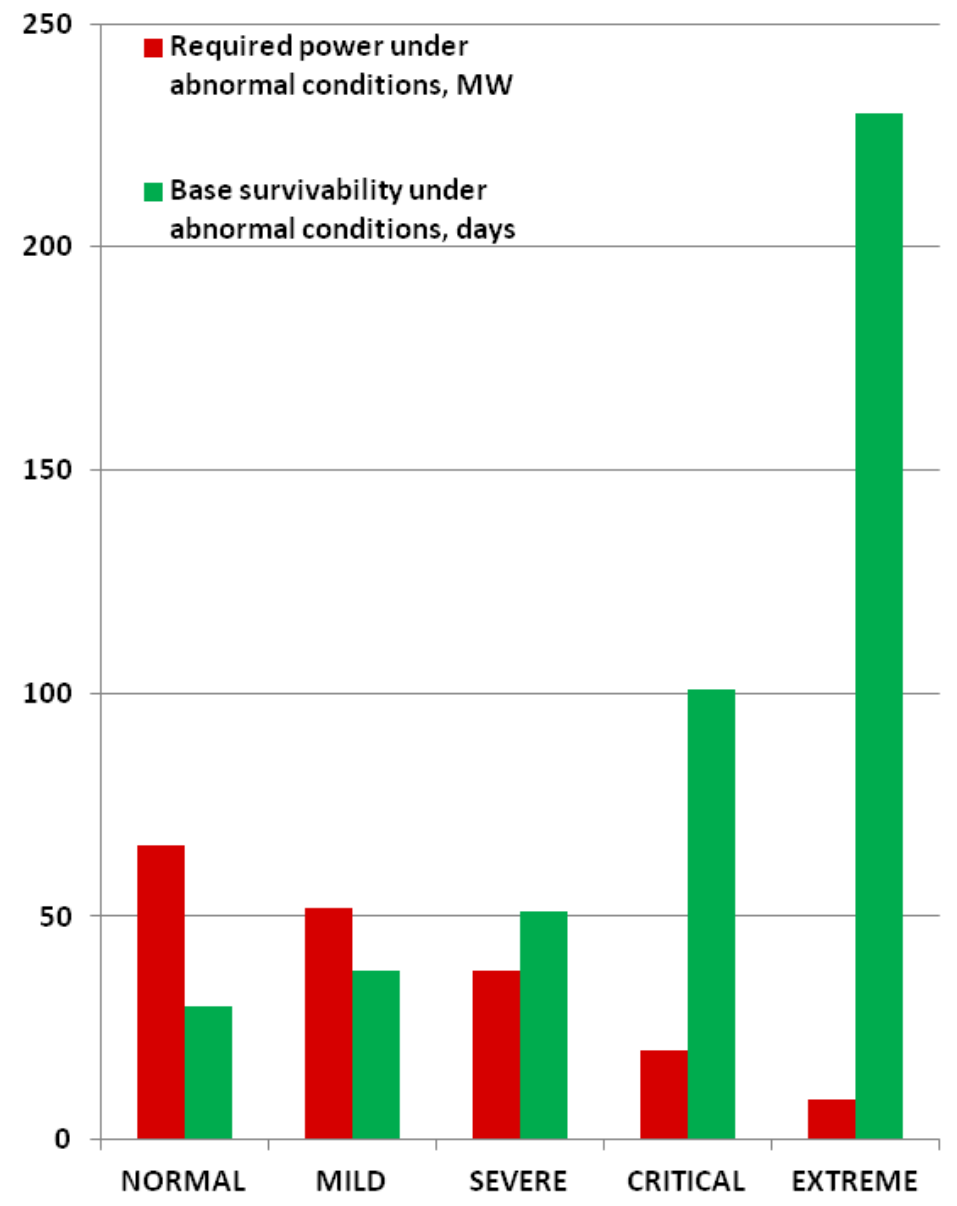

Level of emergency

operating condition

Figure 2: Typical base survivability projection in response to various levels of emergencies.

\section{ELECTRICAL MODEL OF THE NOTIONAL BASE}

The spreadsheet described above can only yield rather macroscopic results. More detailed performance can be obtained only after a model of the electrical infrastructure of the base and of the loads present therein is made. Key to a successful strategy for ensuring energy security is the method used in the assessment of the present status and the quantification of the potential benefits anticipated from any new course of action. Since extensive measurements and system monitoring are expensive in terms of manpower, physical resources, and time resources, computer modeling and simulations constitute the best tool to achieve our goal. Moreover, real-time requirements for measurements and communications in microgrids suggest added rigor due to the short distances involved, faster dynamics, and rapid fluctuations in both load and generation [18] Thus, the selection of a software platform and a suitable level of modeling and simulation capable of delivering the needed results in a readily intelligible form is critical to this research. It should be clear, however, that, given the very special nature of the subject of study, namely the Navy bases in the CONUS, and their broad range of characteristics dictated by the variety of their missions, considerable development in the application of the software is necessary to accomplish the task. In fact, it is improbable that commercial software designed for the requirements of conventional electrical utility networks can be used as a turn-key project; more likely, it will be necessary to supplement the tool with specific technical and operational know-how for its successful implementation in enhancing the energy security of Navy bases.

The decision on the correct level of modeling and simulation is guided by the following considerations:

1. Whether real-time simulation and energy management are desirable 
2. The variables that need to be taken into account (electrical, thermal, system and/or component efficiencies, instantaneous and/or average values, volumes and weights, reliability figures, etc.)

3. Computational details:

a. The time step of the computation (resolution of the variables in time)

b. Model order, namely the level at which performance information is desired (e.g. subsystem level, like a power converter, or component level, like switching transistors)

c. Simulation time (calculations may be long, up to several hours, thus, economy of data generated, effective use of the system's data storage, and computational speed are important especially if real-time or near real-time performance is desired)

4. Calculation types (transient simulations versus steady state simulations)

5. The required degree of interaction among the operator, the deployed monitoring system, and the supervisory program (human interface, integration with existing hardware, interactivity, real-time control)

6. The sophistication of the program output in the form of reports, tabulations, plots, or more importantly, of operational displays (graphical user interface, dashboards, data and system visualization)

7. Interface with the local utility (using compatible software platforms simplifies the management of the tie point between the base and local utility)

The model of a Navy base can be developed using a number of commercial software programs currently available. Table 1 shows the distribution system analysis software packages examined in the course of this study. The examination was done within rather stringent time and funding constraints and, therefore, is not exhaustive and certainly not as in depth as would be necessary. As can be seen, no software package has all the desired characteristics [19]. Additionally, all would have to be adapted by the user to the modeling and simulation needs of the CONUS Navy bases. This means that no software package can fulfill all the needs of our specialized application in its "as is" state becoming a turn-key task, but a fair amount of what can be called technology development is necessary before it becomes a useful tool for Navy personnel and planners. It must also be added that the classification presented here is evolving in time, as programs upgrades tend to offer constantly more options.

Table 1. Distribution system analysis software programs surveyed by UT-CEM in this study

\begin{tabular}{l|c|c|c|c|c|c}
\hline & Paladin & ETAP & $\begin{array}{c}\text { Sim } \\
\text { Power }\end{array}$ & CYMDist & OpenDSS & GridLab-D \\
\hline OpenSource & No & No & No & No & Yes & Yes \\
\hline Renewables & Yes & Yes & Partial & Yes & Yes & Yes \\
\hline EVs & No & No & No & No & No & No \\
\hline $\begin{array}{l}\text { Price-Influenced } \\
\text { Loads }\end{array}$ & No & No & No & No & No & Yes \\
\hline Energy Storage & Yes & Yes & Yes & No & Yes & Yes \\
\hline Geo-display & $\begin{array}{l}\text { with follow- } \\
\text { on product }\end{array}$ & $\begin{array}{l}\text { with follow- } \\
\text { on product }\end{array}$ & No & Yes & Partial & No \\
\hline Learning Curve & Moderate & Moderate & Smooth & Moderate & Steep & Steep \\
\hline GUI & Yes & Yes & Yes & Yes & Yes & No \\
\hline Custom Models & Yes & Yes & Yes & No & - & - \\
\hline $\begin{array}{l}\text { Time Domain } \\
\text { Transient }\end{array}$ & Partial & Partial & Yes & - & - & - \\
\hline
\end{tabular}

The model of the notional base was developed for practical reasons using the software module DesignBase, provided by Paladin, although the same task could have been accomplished with other programs. In fact the notional base was also modeled with other software packages, although to a less detailed level due to time constraints. Thus our use does not represent an endorsement of the product to the detriment of others, as the same examples reported herein could have been run with other packages as well. 
In order to proceed with the modeling of the notional base, it is necessary to decide first on a topology for the electrical system. Many different schemes have been used by utilities, but the special nature of the system in question and the criticality of its mission demand that reliability of service and redundancy take precedence over other considerations, including cost. Therefore, it can be assumed that some form of distribution architecture based on a double circuit be used, as shown schematically with its major distribution lines in Figure 1. It is further assumed that these circuits and their service feeds and loads are interconnected according to the so-called breaker-and-a-half scheme. This is justified on the basis that, whereas a comparison of various configurations is complex, system and mission specific, and with figures of merit giving only general guidance, the breaker-anda-half scheme is one of the most practical and reliable ones [20,21].

This topology is illustrated schematically for convenience in Figure 3: it consists of two separate buses at the same voltage and to which all loads are tied via local breakers. Additionally, connections between the two rails are possible at regular intervals by means of cross-over breakers that are normally open but can close if needed to re-route power. Thus, this distribution scheme resembles a step ladder where the sides of the ladder are the two main buses and the rungs are the load breakers plus the cross-over breakers (this topology can be implemented also with suitable physical separation between the two rails for added security).

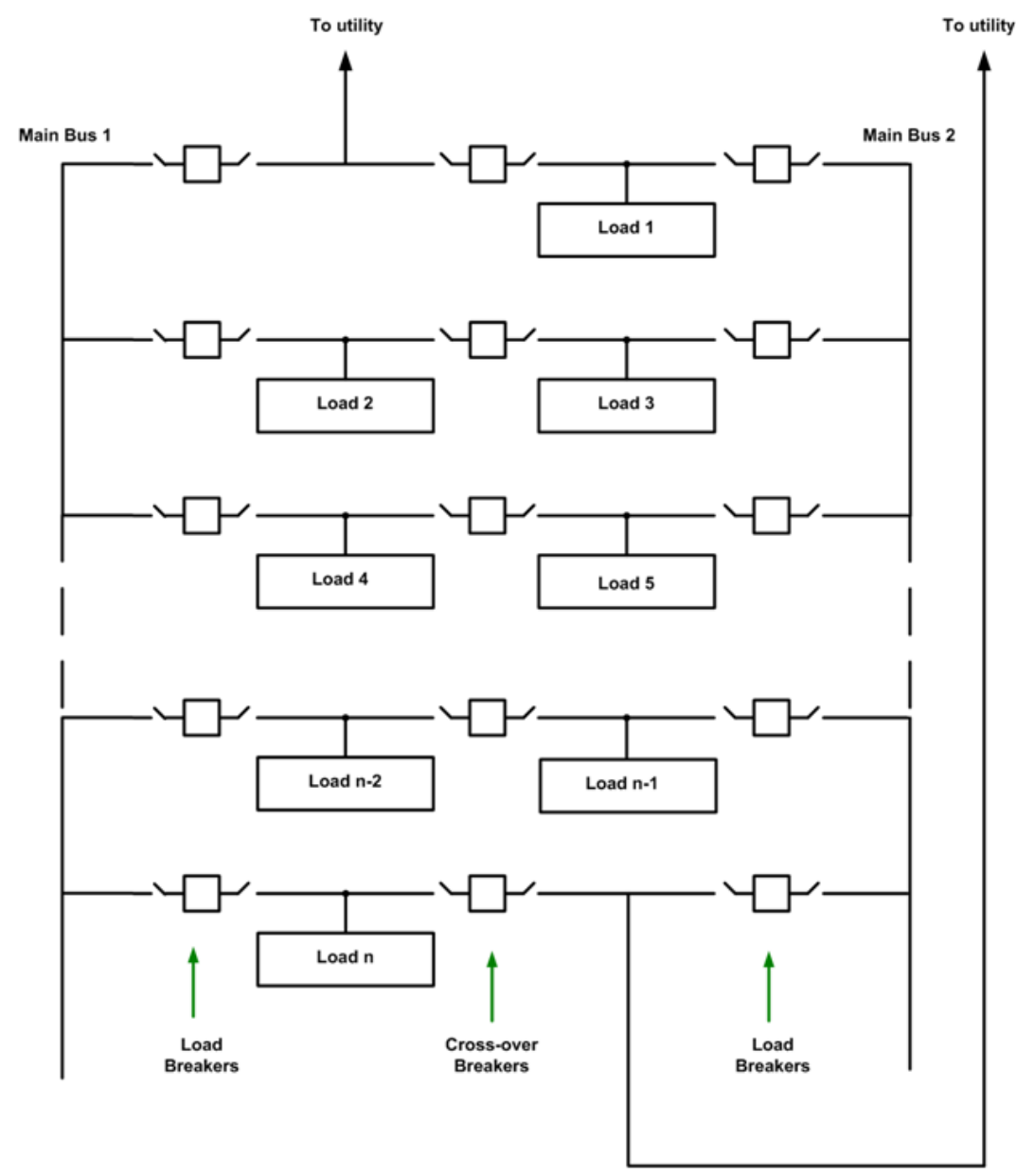

Figure 3: Schematic diagram of the breaker-and-a-half topology used for the notional base.

A list of the loads and power sources used in the model of the notional base is given in Table 2. It can be seen that many of the loads are aggregates of several others: the degree of granularity depends on the fidelity required. Even as shown implemented at the distribution level, the system is composed of several elements as the list in Table 3 shows. 
Table 2: Loads and power sources of the notional base model

\begin{tabular}{|c|c|}
\hline Item & Number \\
\hline Substation connection to utility & 1 \\
\hline Generating station & 1 \\
\hline Solar station & 1 \\
\hline Wind station & 1 \\
\hline Renewable interface station & 1 \\
\hline Air Field & 1 \\
\hline Data Center & 1 \\
\hline Communication center & 1 \\
\hline Headquarters and clinic & 1 \\
\hline Office clusters & 3 \\
\hline Storage tanks and shops & 1 \\
\hline Material handling / & 1 \\
\hline maintenance & 1 \\
\hline Warehouse complex & 2 \\
\hline Residence clusters & 1 \\
\hline Amenities and miscellaneous &
\end{tabular}

Table 3: Composition of Notional Base at the distribution level

\begin{tabular}{|l|c|}
\hline \multicolumn{1}{|c|}{ ITEM } & NUMBER \\
\hline Buses & 58 \\
\hline Branches & 63 \\
\hline Circuit Breakers & 18 \\
\hline Major Load Points & 12 \\
\hline
\end{tabular}

\section{SIMULATION RESULTS}

Several preliminary simulations were performed on the power system of the notional Navy base. The simulations addressed a variety of operating situations including base operation with power from the external utility only, powering the base from a combination of local utility and on-base solar and wind power sources, islanded operation using an on-base power station, islanded operation using an on-base power station in connection with wind and solar sources, and transient events including a transformer failure and the instabilities that may be induced during the transition to islanded operation. Some typical results are reported in what follows.

The notional base is modeled as connected to the local utility via two independent transformers and breakers, labeled 1 and 2, and to the local generating station, the solar array, and the wind farm respectively via main breakers 3, 4, and 5. Thus, if Main Breakers 1 and 2 are closed and Breakers 3-5 are open, the base is connected to the utility supply only (normal baseline system). The resulting load flow calculations show that the total base load is roughly evenly split between the two main branches, $32.9 \mathrm{MW}$ from the branch powered by Transformer 1 and 25.5 MW from the branch powered by Transformer 2, for a total of 58.4 MW (Figure 4). 


\section{Transformer 1}
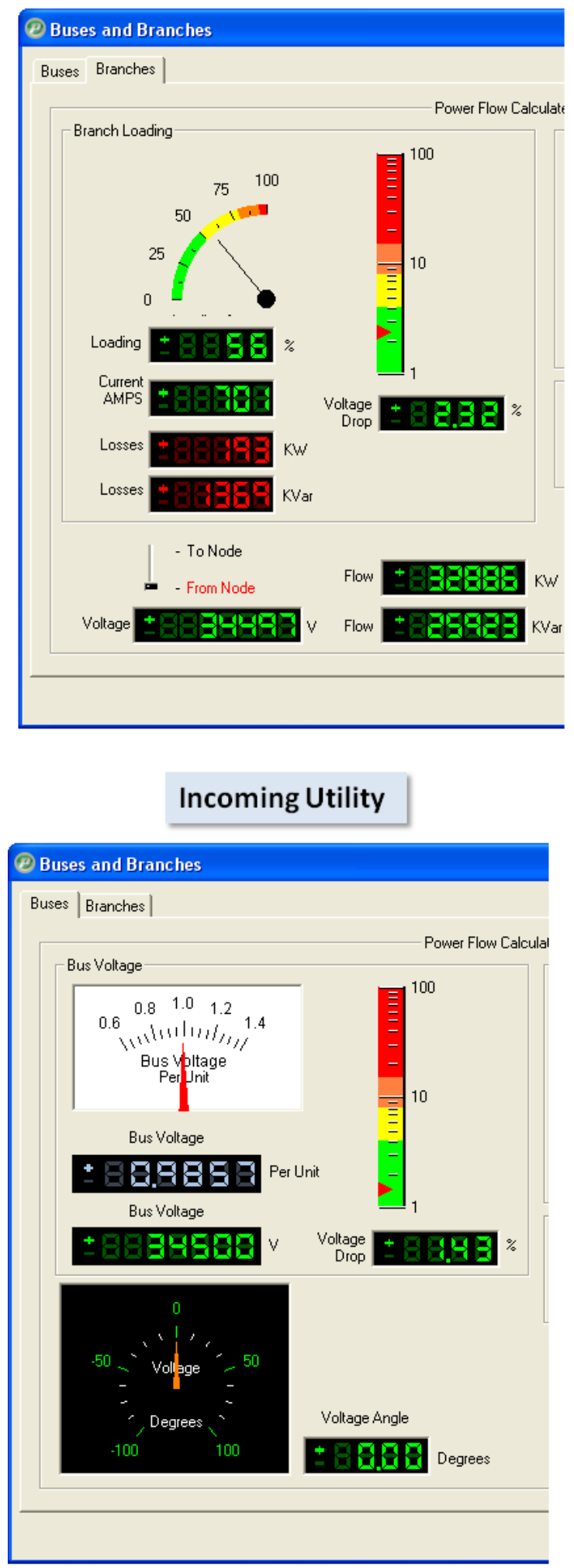

Transformer 2

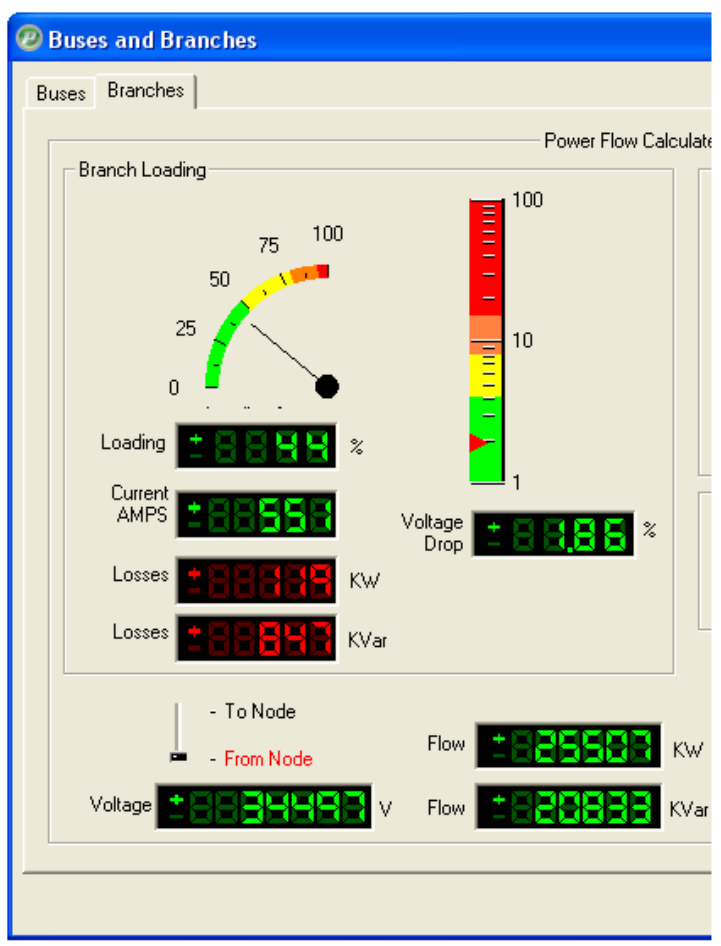

\section{Material Handling \& Maintenance}

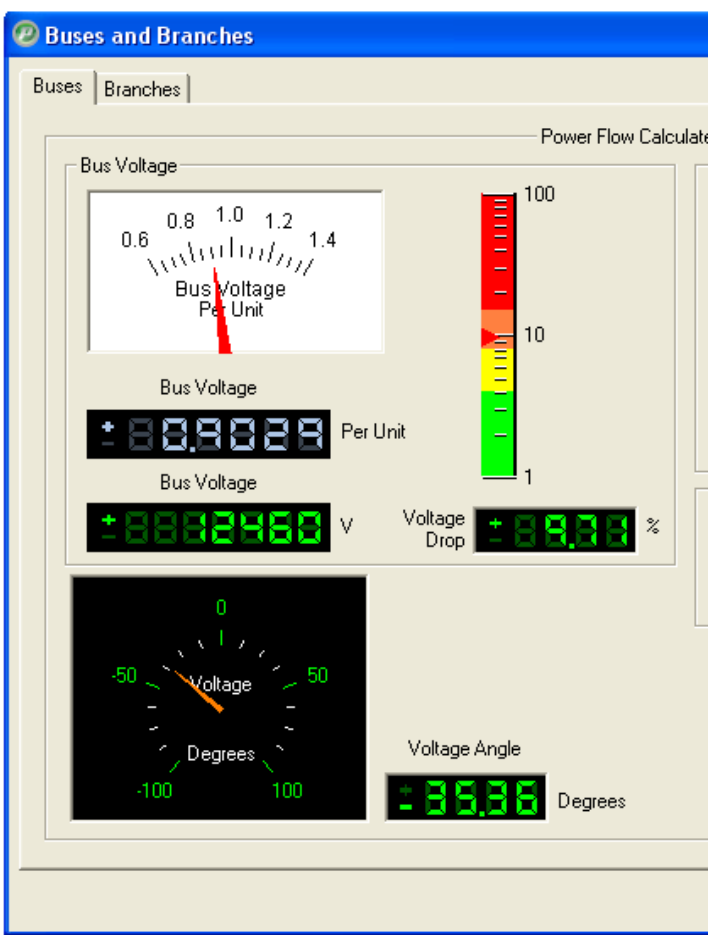

Figure 4: Main transformer utilization and voltages at utility tie and at lowest point (baseline system). 
The point where the voltage level is lowest occurs at the Material Handling Load location. The voltage at that point is $12,460 \mathrm{~V}$, down $9.71 \%$ from the rated voltage of $13,800 \mathrm{~V}$. This would indicate that the present bus conductors can barely maintain the voltage within $10 \%$ of rated even under normal operating conditions. One possible explanation is that the base growth over time may have outrun the capacity of the electrical infrastructure which should, therefore, be upgraded.

If one assumes that information is available about the voltage level at the utility tie-in, the load power demands at the various load points, and the load power factors over a period of time, the time evolution of voltage levels at different points in the system can be traced. For example, Figure 5 shows the voltage evolution at the Material Handling and Maintenance station over a 24-hour period as a result of the utility voltage variation (shown), the variation in time of the load demand and power factor at its own load point (also shown), and the variation of power demand and power factor at all other loads (not shown).

\section{Material Handling Load Node}

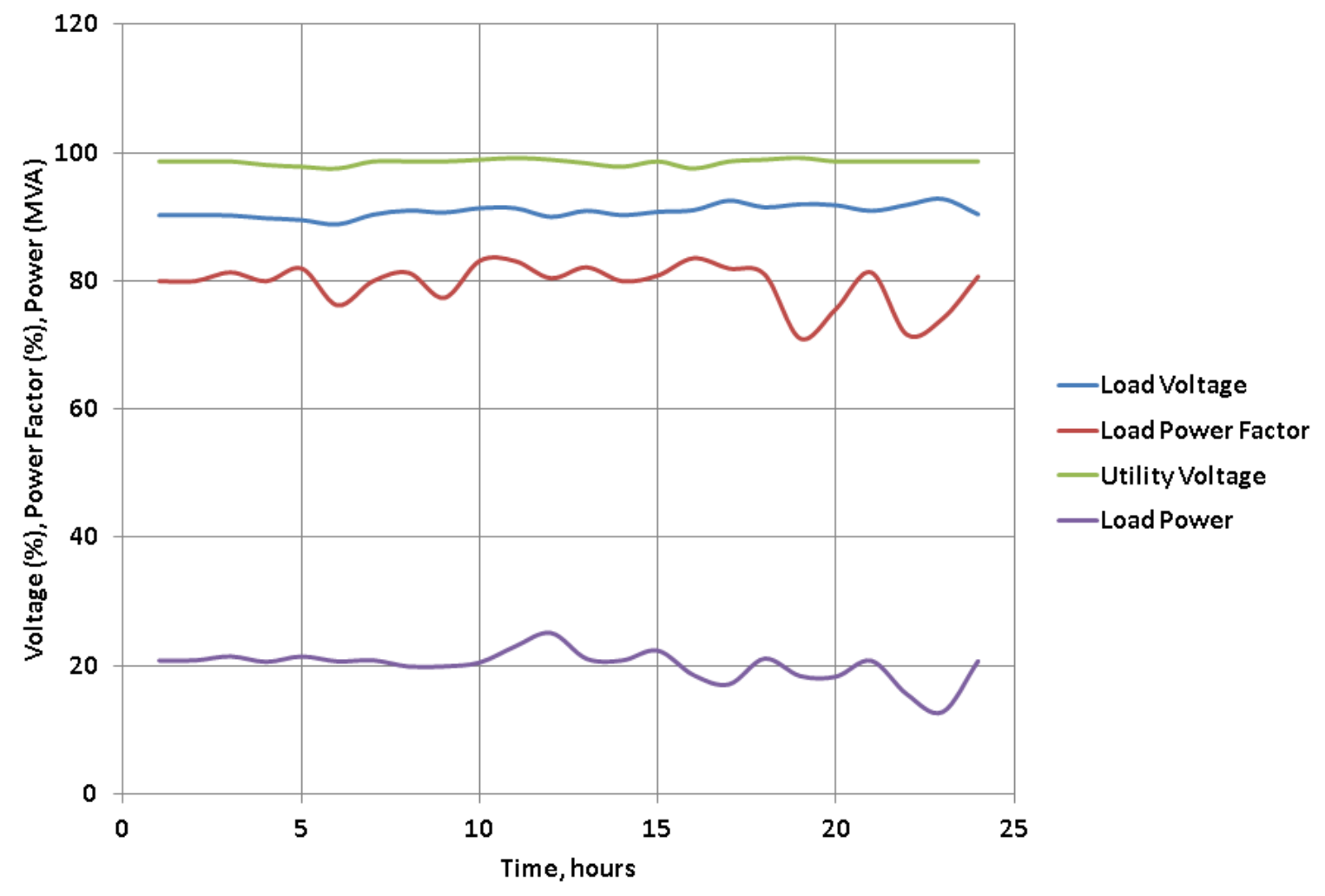

Figure 5: Voltage variation at Material Handling station over a 24 hour period (Baseline system).

Another example run was for operation in full islanded mode. This case is realized by keeping Main Breakers 1 and 2 open, but 3-5 closed. The main results are summarized in Figure 6: the generating station still provides essentially all reactive power, but its real power output is reduced to $55.6 \mathrm{MW}$, being assisted by 7.2 MW of solar power and 4.0 MW of wind power. As expected, albeit somewhat ironically, the presence of renewable resources forces the power station to operate now at a lower power factor of $77 \%$ (down from $82 \%$ when connected to the utility). Thus, although the base is expected to need $66 \mathrm{MW}$ of real power, the reactive power needed forces the local generator to be rated at least at 85 MVA. 


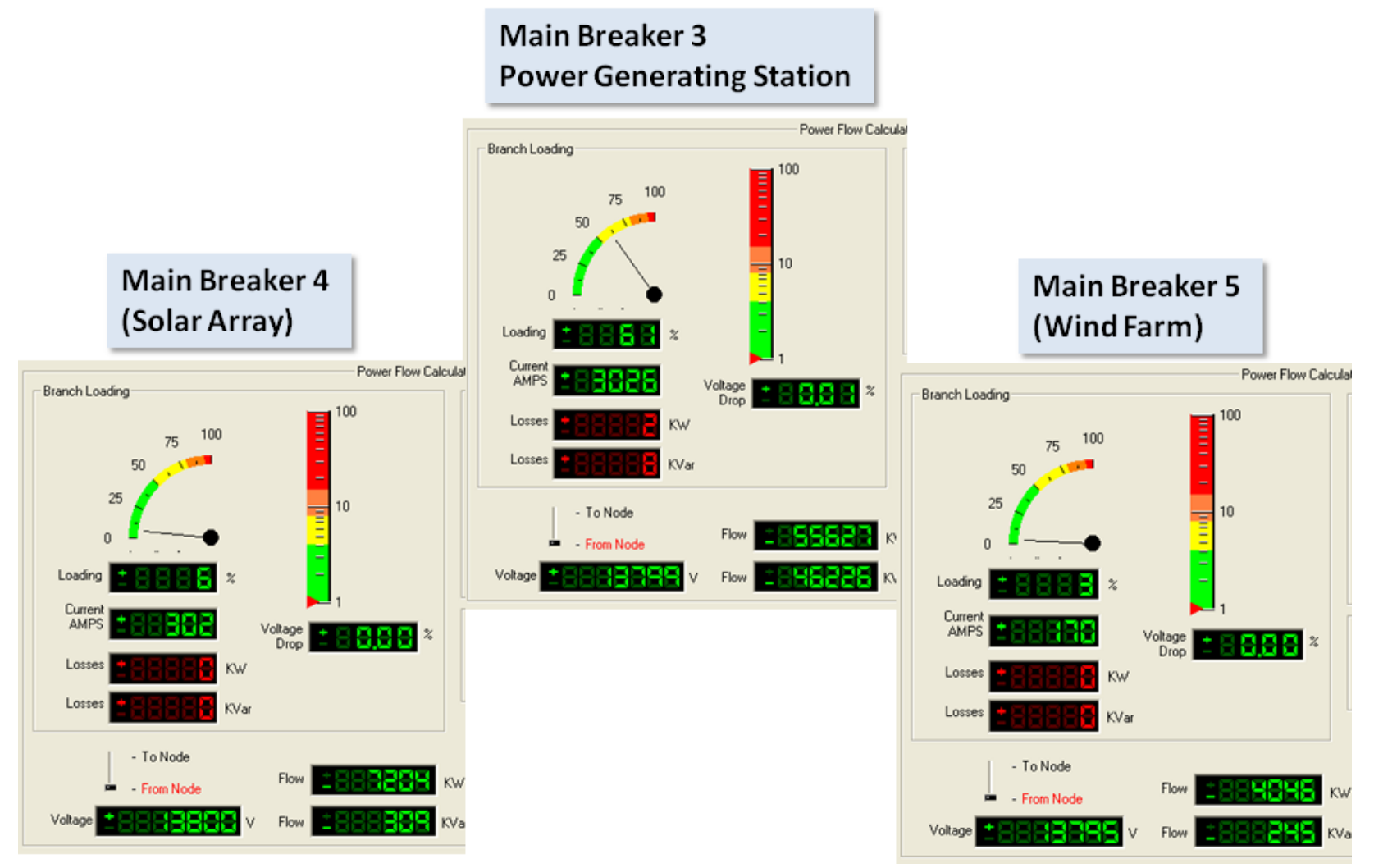

Figure 6: Operation with local generating station and renewables.

As an example of transient analysis, one can examine in detail the transition from normal, utility-tied operation to that of fully islanded operation. This can be the result of a planned reconnection or be triggered by an emergency. In either case, the system will open both Main Breakers 1 and 2 and close Main Breaker 3. Furthermore, in an established sequence, the grid controls will close all the cross-over breakers in the breakerand-a-half scheme configuration. Figure 7 shows the current transients at some of the main breakers. It is important to note that the grid-tied energy sources were allowed to operate as islanded despite well-known current anti-islanding requirements [22]. In addition, these sources were allowed to provide reactive power through their inverters as is common in the analysis of distribution systems concerned with renewables [23] .

\section{SHORE POWER}

Shore power for direct interface with docked ships was included as part of the load system labeled "Material Handling/Maintenance”, for which a total of 12.8 MW was calculated. This power was specified as consisting of several $480 \mathrm{~V}$ nominal at no-load, $60 \mathrm{~Hz}, 400 \mathrm{~A}$ outlets and some 4,160 V, $60 \mathrm{~Hz}$, ones [24]. As for other types of power (e.g. dc power or $400 \mathrm{~Hz}$ power) it was assumed that they would be provided from proper conversion of these two primary sources of electric power to which they would appear as a load. It must be noted that, as a ship's electric service power is specified to be $450 \mathrm{~V}$ minus $5 \%$ at a minimum ( $427.5 \mathrm{~V}$ ), this would mean a maximum deviation from no-load voltage $(480 \mathrm{~V})$ of $11 \%$. In the discussion of the data shown in Figure 4 above, it was observed that the system as designed was capable of being within this limit, albeit with a small margin of safety.

It should also be pointed out that the voltage from the $480 \mathrm{~V}$ shore power supply, as measured at the ship's main switchboard should not exceed $462 \mathrm{~V}$ [25]. This is a rather stringent requirement but it could not be studied in detail within the confines of this project, especially because it would have involved detailed information about the cables used in the connection to the ship. 


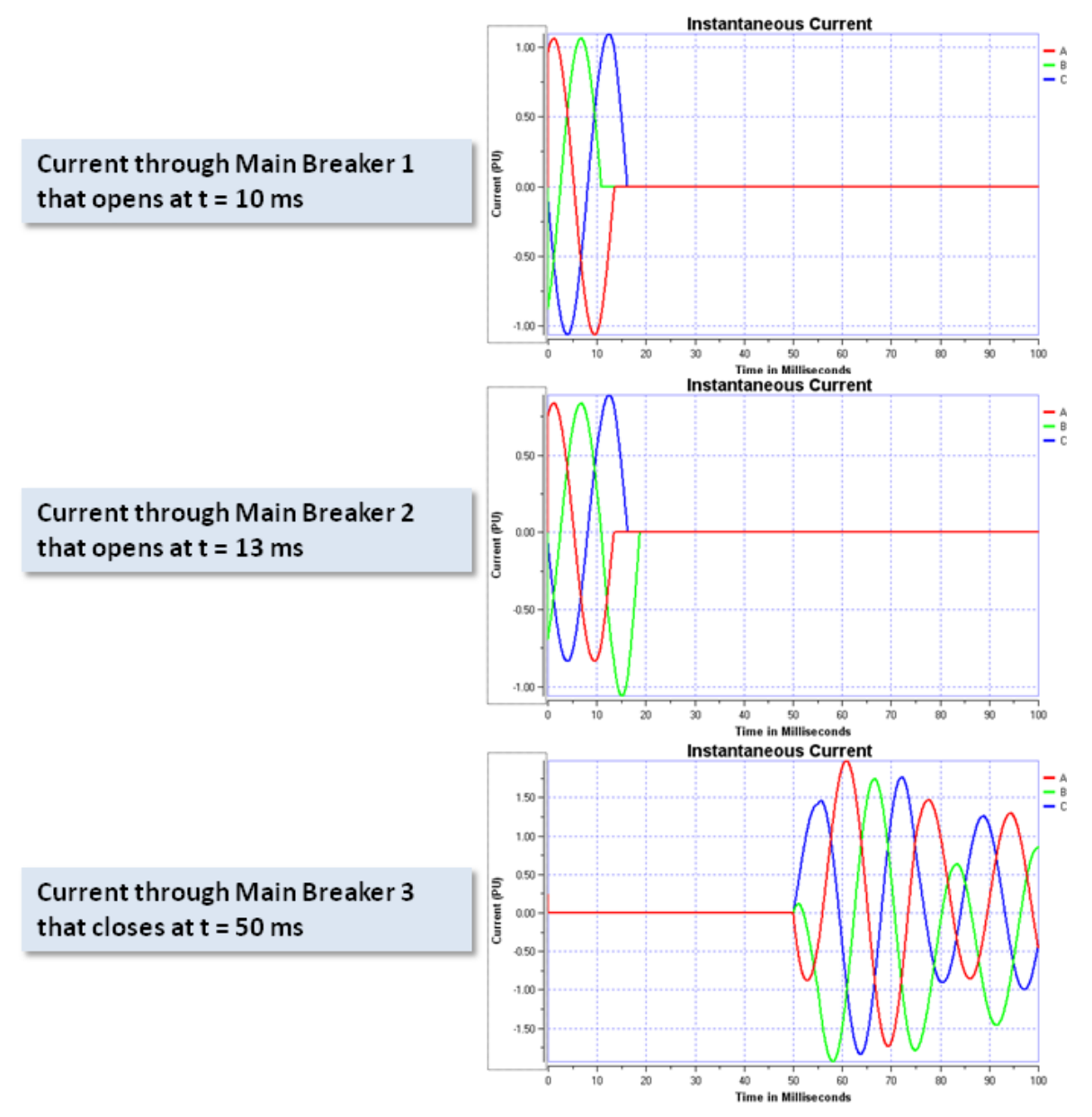

Figure 7: Transients following reconfiguration of the base grid for islanded operation.

\section{INTEGRATION OF RENEWABLE RESOURCES}

The impact of emerging technologies, such as photovoltaic (PV) arrays and electric vehicles (EV), was also investigated. Forthcoming fleets of electric vehicles [26], increasing number of residential solar panels, and new energy storage technologies concern utilities across the United States insofar as it affects asset management. Since appropriate military data were not available, civil sector data were used to highlight the strength of modeling of distribution power systems. The University of Texas at Austin Center for Electromechanics (UTCEM) has been examining data of residential consumption and generation for a working smart-grid community of 735 homes, 178 of which are equipped with solar panels. This ongoing development is known as The Pecan Street Project [27]. This community demands approximately $1.5 \mathrm{MW}$ and generates $0.5 \mathrm{MW}$ (aggregate) through roof-mounted photovoltaic panels. Furthermore, the community expects to have nearly 100 electric vehicles of which 60 have already been deployed (Chevy Volts and Nissan Leafs). Data on residential consumption and solar generation have been collected and are available for the last two years. Data on the recharging patterns of electric vehicles have just begun to be collected as the technology introduction is of very recent date. Pecan Street, Inc. collected and provided UT-CEM experimental charging profiles to predict the impact of electric vehicles on its residential community. The experimental data were assumed to be valid for a notional base installation. To model un-correlated charging behavior in all vehicles, starting charge time, charge duration, and charging level were randomized. Therefore, using actual high fidelity electricity consumption data collected from the civilian sector, the potential impact to a Navy base’s grid can be studied.

Assuming that the data collected in the civilian sector can be transferred to a Navy installation, UT-CEM has inspected the potential impact of PVs and EVs for a naval base. The main conclusion is that the major impact is 
to changes in distribution transformer utilization (Figure 8). It was determined that most of the electrical impact on a grid stems from photovoltaic arrays rather than electric vehicles and have a significant impact on the diurnal power factor of the distribution system.
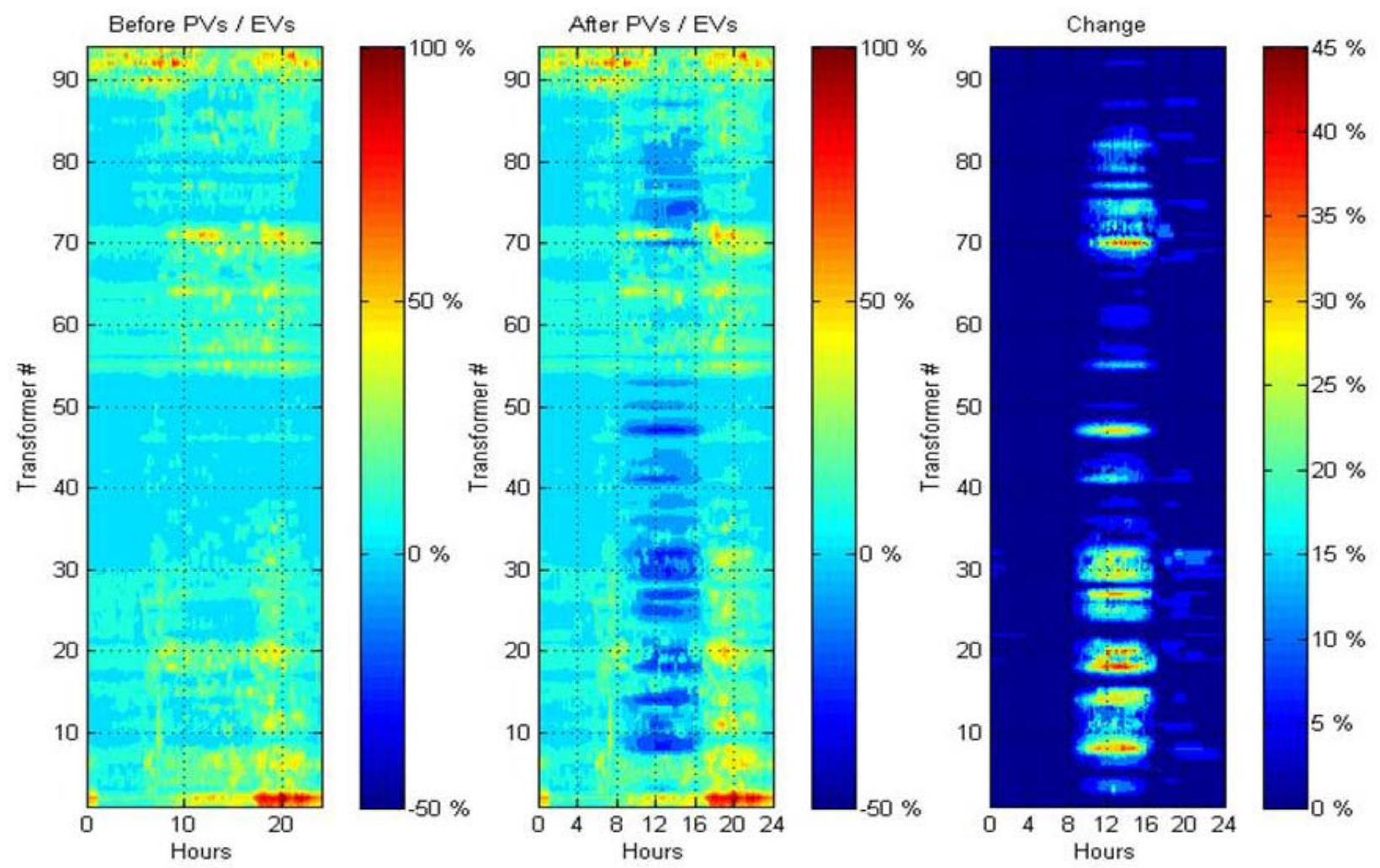

Figure 8: Transformer utilization (\%-VA, 1-min. interval) aggregated by UT-CEM

The left panel of Figure 8 shows transformer utilization (\%-VA) for all 94 transformers for a 24-hour period before inclusion of the $178 \mathrm{PVs}$ and $100 \mathrm{EVs}$ in the computer model of the Naval base. As seen from the red regions, some transformers normally operate close to rated capacity (80-100\%). This practice is consistent across many utilities in the United States.

The center panel shows transformer utilization (\%-VA) after the inclusion of all PVs and EVs in the computer model. As seen from the blue regions (between $8 \mathrm{AM}$ and $4 \mathrm{PM}$ ), some transformers experience a diurnal reverse-flow while others do not. The amount of reverse flow depends on the ratio between PV-generation and residential consumption behind each distribution transformer. As noticed from the changes in the yellow regions, the EV impact is small when compared to PVs.

The right panel shows the change in transformer utilization. While most of the utilization change is in the $0-5 \%$ region (dark blue), in some locations the change does reach $30-40 \%$. This change, however, is not due to EVs as commonly expected; it is due to PVs producing more power than is being consumed by the residential loads.

UT-CEM's integration of these field-collected data into naval base models increases confidence in the results and may guide realistic decision making, safe practice, and service schedules in naval base energy management. This not only permits assessing the impact of the renewable energy sources and electrical vehicles on Navy installations in regard to effectiveness and reliability, but also running predictive financial simulations to determine when renewable energy sources and emerging technologies stop becoming economical. 


\section{OPERATOR INTERFACE}

With the ultimate goal in mind of real-time control, performance optimization, protection against unexpected catastrophe, and orderly recovery from unforeseen events of a CONUS Navy base, it is imperative that the human-machine interface be designed to condense the multitude of data into an easy to use graphical panel, which can be called the electrical system dashboard.

The notional Navy base used in the course of this investigation consists of, at the distribution level, 58 buses, 63 branches, 18 breakers, and 12 load centers (Table 3). Even in its simplicity, to evaluate a single scenario, the output in text/tabular format results in a printout of several hundred pages. This is impractical for real-time control. The software can output all pertinent details in the form of text and tables but these are difficult, if not altogether impossible, to analyze in a timely manner. Furthermore, the operator must be able to take action quickly, literally with few simple entries: writing out code on a command line is time consuming and prone to error.

Finally, considering that each of the macroscopic entities (e.g., each load center) describing our notional base is really given by the consolidated behavior of several, perhaps even hundreds of subsystems (e.g., pumping units), and that each subsystem is itself made up of many individual components (e.g., variable speed drive, motor, pump), one can appreciate the fact that the actual base model, when completely detailed, will contain several thousand elements.

All these reasons provide sufficient justification for insisting on the quality of the program's graphical user interface (GUI). The GUI can be configured to operate at different levels of detail. Thus, one can envision that a GUI for each of the levels mentioned above, namely distribution, subsystem, and component, can be designed to display the desired information. Other levels of GUI can be added as desired, and in fact, it is easy to realize that a multi-level GUI is almost a necessity for even a moderately complex real base. Proper navigational aids to move from one level to another must be provided and the points of entry for the operator's command to intervene on the system must be clearly highlighted.

\section{CYBER-SECURITY}

The issue of cyber-security, although mentioned, was beyond the scope of this study and has not been developed. The subject is a very specialized discipline that involves agent identity verification, intrusion prevention and detection, cryptography, and similar matters. A fundamental tenet of the model-based control approach is that the utility's external SCADA system interfaces only with the model, not any of the hardware on the base. When the model shows the SCADA command to be benign, the base control system implements the request. Within the scope of this project, the items addressed were 1) command authorization and 2) violation of established limits and procedures.

Both of these items require programming verification steps to be executed before action is taken on the system to serve as a sort of policed entry point. This could be accomplished externally or internally to the modeling program. The external implementation is believed, at the present time, to be the preferred course of action. It is true that this would entail the use of yet another software package, but it would also leverage the specialized techniques embedded in it to enhance security.

The internal implementation will have to be accomplished using the programming tools made available by the modeling and simulation software. These tools are typically in the form of logic blocks, both analog and digital, that can be combined opportunely to achieve a specific control objective. Commercial modeling and simulation packages of the types mentioned earlier in this study vary widely in the quality of their library of control functions made available to the user and in the extent to which the results of any control scheme can be interfaced with the electrical system blocks properly. In any case, whether accomplished within the modeling and simulation program, with additional software external to it, or even with a combination of both methods, the desired degree of security must be weighed against the inevitable computational overhead incurred.

\section{TEST BEDS FOR EXPERIMENTAL DATA}

Recently, several other microgrid/smart-grid initiatives have been started around the CONUS, mostly centered on university campuses around the Conutry. As an example, one can point to one of the most successful ones, 
namely that at the University of California at San Diego (UCSD) [28]. Coincidentally, the project at UCSD uses the same software package, DesignBase, to model its power system that was used in the course of the present study, as reported above. Since its deployment, the UCSD microgrid has performed very well with no loss of service even through a major blackout that affected the Southwest USA in 2011. This is an experimental confirmation that the strategy advocated in this study is effective. Additionally, the UCSD microgrid interfaces DesignBase with other software packages to control distributed resources and perform the necessary data acquisition. All these projects aim primarily at the optimization of the microgrid, as loads and the availability of renewable resources evolve in time (energy security in the strict sense). However, like the Pecan Street Project of the University of Texas, also the UCSD and similar projects, while providing real life applications of the microgrid concepts, do not have the flexibility for actual experimentation with new systems, since their main focus is to maintain service for the existing microgrid customer loads. Thus, there is a need for intelligent microgrids that can be used for experimental work especially concerning physical security as well as cyber security.

For example, UT-CEM has identified al test bed for studying grid control strategies, new components, and subsystems: the Pickle Research Campus (PRC) located in North Austin and wholly owned by The University of Texas. UT-CEM is also located at PRC. From the electric power standpoint, PRC is a well defined candidate grid within the larger Austin electric grid and monitoring of system variables at the tie point with the local utility is straightforward.

The PRC system requires an average power of $10 \mathrm{MW}$ from the local utility but includes two operational gridtied solar power arrays rated respectively at $300 \mathrm{~kW}$ and $22 \mathrm{~kW}$. Furthermore, UT-CEM has also developed its own local experimental microgrid within the PRC microgrid that can be configured around a MVDC bus or a HFAC bus equivalent in power to $20 \%$ of the total combined power used by the PRC at large [29]. This submicrogrid is fully controllable with distributed loads and independent distributed generators. Using power electronic converters, the generators can emulate the performance and behavior, for example, of a wind power generating plant; thus the PRC system, augmented by the controllable UT-CEM microgrid, can be studied with an effective renewable penetration of more than 20\%. Furthermore, the UT-CEM microgrid is a natural test bed for the study of new components, subsystems, control software and strategies, and response to malicious attack.

\section{ROADMAP TO ENERGY SECURITY}

The roadmap to improving energy security in a Navy base is envisioned in its broad conceptual terms as shown in Figure 9. Its key feature is the fact that all signals to the electric power system, whether external or internal to the base, are mediated by the system's model: only after the model has verified that the received command is not harmful will the electric system be updated. 


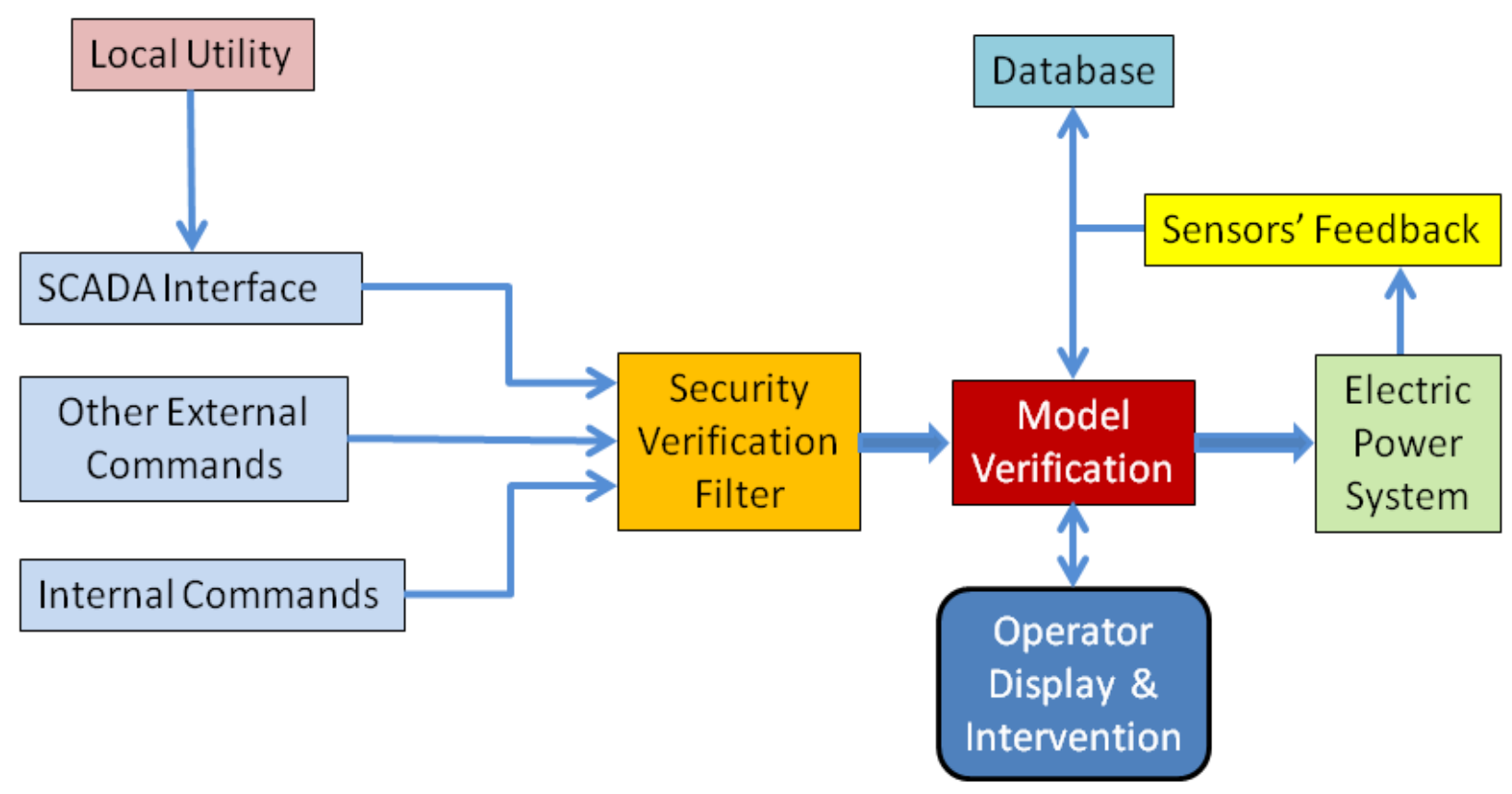

Figure 9: Macroscopic diagram of the desired control system for energy security

Several important steps are included in this macroscopic description of the desired control system, among which are the following:

1. Modeling and simulation validated by data on the existing system (baseline configuration) and extension to new desired configurations (system planning).

2. Gradual implementation of a new system with constant monitoring by direct feedback from deployed meters and sensors and comparison with expected data. Simulations can be run offline at each crucial point prior to implementing a new change. This step will generate a database of possible operational systems with attendant figures of merit and thus, will define a hierarchy of options available to base command.

3. The development of processes and procedures for effective documentation and verification, validation and accreditation (VV\&A) of the simulation models to enable their use for a broad range of Navy installations.

4. Active intervention on the system via the established interface with the program to:

a. modify parameter settings of distributed hardware to achieve optimal performance (interactive control, possibly in real time)

redefine the system into a different configuration based on previous simulation results (system reconfiguration).

Further expanding in time the development process that can lead to enhanced energy security as outlined in Figure 9, we can identify three major steps that detail the work needed for successful implementation: these steps are shown graphically in Figure 10. Again, it is necessary that the supervisory control system be able to operate in real time in order to minimize any latency inserted in the overall process. 


\section{Roadmap to Energy Security}

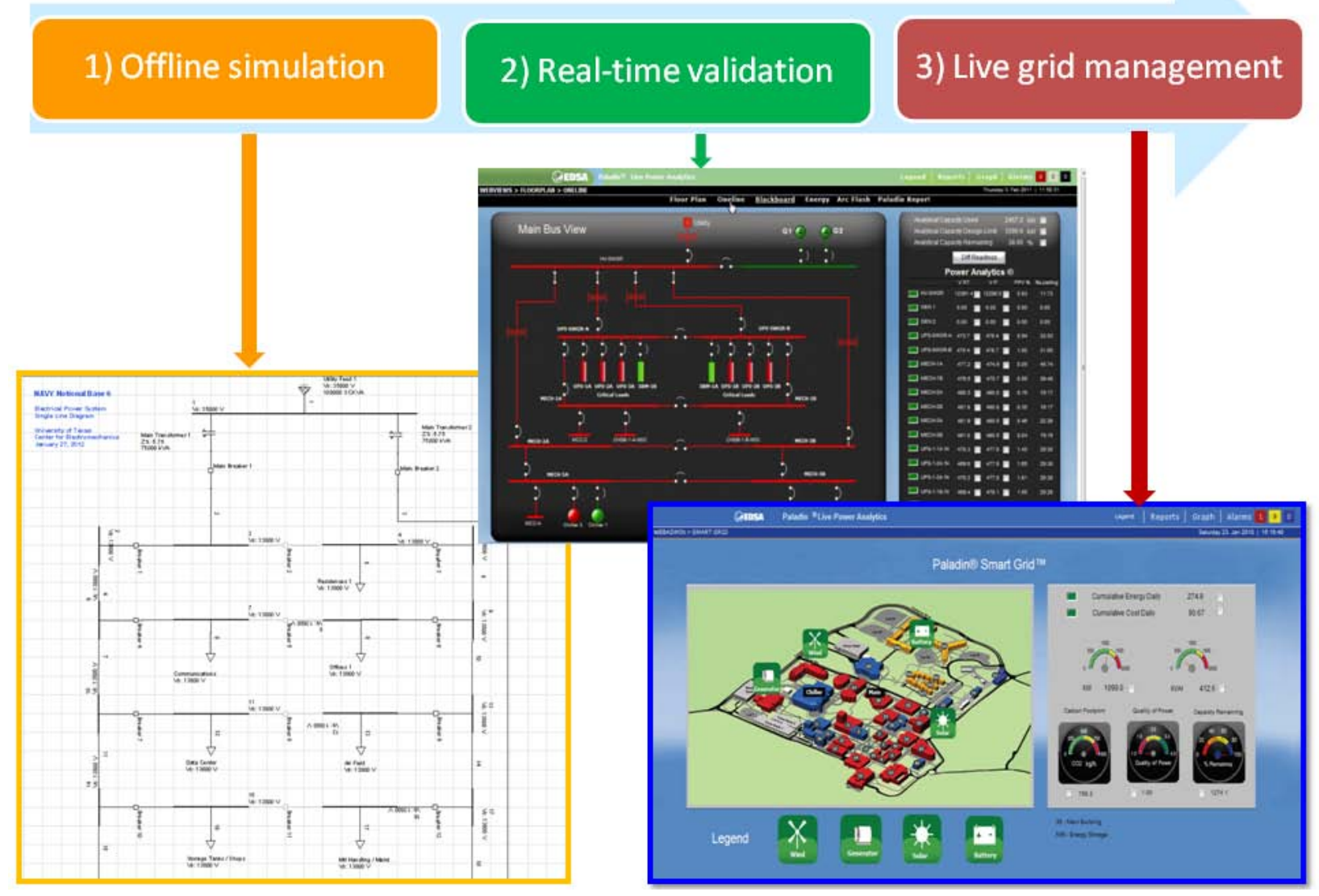

Figure 10: Three-tier energy security and live energy management plan (main graphics from Power Analytics).

To implement this plan, several changes are necessary, in particular regarding the base concepts of operation (CONOPS). Following are some of the basic issues that need attention:

1. Changes to the present infrastructure will be needed. Consideration must be given to:

a. practicality of the changes

b. cost of the changes

c. incremental implementation of the changes guided by funding and the evolution in time of the system as predicted by the modeling and simulation effort

2. Changes to the electrical infrastructure must be coordinated with existing energy and utility infrastructures, notably the water system and the natural gas distribution system, which must be integrated into the overall planning and management of base energy security

3. The relationship with the local utility must be revised and new procedures must be mutually agreed upon in regard to:

a. disconnection from the local utility (islanding) and reconnection [30]

b. control of the renewable energy resources located on base (e.g., typically bases cannot access their own renewables directly, but only through the mediation of the local utility)

c. improved security procedures directed at minimizing the risk of cyber-attacks, especially through the utility SCADA network

CONOPS are difficult to establish in detail ahead of time. As a result, flexibility is required to allow for evolving needs and confront unforeseen challenges. 


\section{CONCLUSIONS}

Ensuring the security of energy resources and enabling continued operations of military, and possibly nearby local civilian, installations in the event of a utility supply disruption is a vital concern. A roadmap to enhance the energy security for CONUS Navy bases has been outlined in this paper. Because of the large number of variables involved and the complexity of the optimization process, this necessarily requires the use of a suitable modeling and simulation platform. Since real-time simulation and energy management is highly desirable, the processing of data from field sensors and meters and its output into a readily intelligible format can only be accomplished by means of a sophisticated graphical user interface.

The approach was tested on a notional Navy base with the intention to help define a tool for the following practical objectives:

- Develop a template for a base general enough to be applicable to most real life implementations

- Define its optimal electrical system architecture

- Estimate the needed infrastructure

- List the equipment supporting the expected loads

- Assess the general power requirements at each load center and overall

- Anticipate the possible reconfiguration schemes based on expected operational scenarios and their impact on the various components

- Determine required redundancies

- Assess system stability and protection in all expected configurations

- Study power quality issues and transient effects on system performance

- Establish component stress levels and required rating

- Estimate needed amount and type of renewable energy

- Estimate needed amount and type of energy storage

- Gain insights into the required control scheme and security thereof

- Evaluate potential vulnerabilities to energy security and design effective countermeasures

- Develop management plans for extended utility power outages and islanded operation

- Provide an effective tool for personnel training

This study outlines a strategy for moving toward a higher level of energy security for Navy bases in the continental USA founded on the concept of model-based control.

\section{REFERENCES}

[1] K. Eickmann, R. E. Hebner, D. Greenwood, W. E. Harrison III, J. Mattice, J. J. B. Porter, C. Ryan, D. F. Swink, J. Snook and B. C. Young, "Task Order 0019/CLIN 0012: WPAFB energy neutral installation initiative," Sept. 2010.

[2] R. Mabus, "Remarks," Navy Energy Forum, Oct. 13, 2011.

[3] F. C. Monastero, "Model for success," GRC Bulletin (http://geothermal.org/articles/coso.pdf, Viewed March 28, 2012), pp. 188-194, Sept. 2002.

[4] U.S. Department of Energy, "U.S. Navy San Clemente Island," http://www1.eere.energy.gov/femp/technologies/renewable_san_clemente.html, viewed March 28, 2012

[5] L. Saunders, "NAVFAC Southwest solar carport projects save energy and money," http://www.navy.mil/search/display.asp?story_id=36446, viewed March 28, 2012.

[6] K. R. Davey and R. H. Hebner, "A new strategy for management and reconfiguration of self-contained power systems," IEEE Transactions on Power Delivery, vol. 21, no. 3, pp. 1565-1570, July 2006.

[7] S.V. Valentine, "Emerging symbiosis: renewable energy and energy security", Renewable and Sustainable Energy Reviews, no. 15, pp.4572-4578, 2011.

[8] U.S. DOE, [Online]. Available: http://buildingsdatabook.eren.doe.gov/. [Accessed September 28, 2011].

[9] U.S. DOE, [Online]. Available: http://www1.eere.energy.gov/buildings/. [Accessed September 28, 2011].

[10] U.S. DOE, [Online]. Available: http://apps1.eere.energy.gov/buildings/tools_directory/alpha_list.cfm. [Accessed September 28, 2011]. 
[11] U.S. DOE, [Online]. Available:

http://www.energysavers.gov/your_home/appliances/index.cfm/mytopic=10040. [Accessed September 28, 2011].

[12] D. Westphalen and S. Koszalinski, "Energy Consumption Characteristics of Commercial Building HVAC Systems Vol II," A.D. Little, October 1999. [Online]. Available:

http://apps1.eere.energy.gov/buildings/publications/pdfs/commercial_initiative/hvac_volume2_final_rep ort.pdf. [Accessed September 28, 2011].

[13] U.S. NREL, [Online]. Available: http://www.nrel.gov/docs/fy06osti/38601.pdf. [Accessed September 28, 2011].

[14] J. P. Guyer, "Introduction to electrical power requirements for buildings," Continuing Education and Development, Inc., 2010. [Online]. Available:

http://www.cedengineering.com/upload/Intro\%20to\%20Electric\%20Power\%20Requirements.pdf. [Accessed September 28, 2011].

[15] W. J. McGuinness, B. Stein and J. S. Reynolds, Mechanical and electrical equipment for buildings, John Wiley, 1980.

[16] D. P. Mehta and A. Thumann, Handbook of energy engineering, Fairmont Press, 1989.

[17] D. M. Considine, Energy technology handbook, McGraw-Hill, 1977.

[18] F. M. Uriarte, R. E. Hebner, A. Kwasinski, A. L. Gattozzi, et al., "Technical Cross-fertilization between Terrestrial Microgrids and Ship Power Systems," in 2012 ESRDC 10th Anniversary Meeting, Austin, TX, Jun. 4-6, 2012.

[19] D. T. Rizy and R. H. Staunton, "Evaluation of distribution analysis software for DER applications," Oak Ridge National Laboratory, September 30, 2002.

[20] D. Nack, "Reliability of substation configurations," 2005.

[21] T.-F. Tsao and H.-C. Chang, "Composite reliability evaluation model for different types of distribution systems," IEEE Transactions on Power Systems, vol. 18, no. 2, pp. 924-930, 2003.

[22] IEEE Std 1547-2003 Interconnecting Distributed Resources with Electric Power Systems.

[23] E. Liu and J. Bebic, "Distribution System Voltage Performance Analysis for High-Penetration Photovoltaics," Available [online] http://www1.eere.energy.gov/solar/pdfs/42298.pdf2008 [Accessed January 15, 2013].

[24] MIL-HDBK-1025/2, Dockside Utilities for Ship Service, May 1, 1988

[25] S9086-KY-STM-010/CH-320R2, Naval Ships’ Technical Manual, Chapetr 320, Electric Power Distribution Systems, April 21, 1998

[26] J. R. Aguero, P. Chongfuangprinya, S. Shao, L. Xu, et al., "Integration of plug-in electric vehicles and distributed energy resources on power distribution systems," in IEEE Electric Vehicle Conference, 2012, pp. 1-7.

[27] A. Toliyat, A. Kwasinski, , and F. M. Uriarte, "Effects of high penetration levels of residential photovoltaic generation: Observations from field data," in International Conference on Renewable Energy Research and Applications (ICRERA), Nagasaki, Japan, Nov. 11-14, 2012.

[28 ] http://www.poweranalytics.com/company/pdf/M-12-GE-PPT-X-00103\%202012\%20UCSD\%20Virtual\%20summit.pdf [Accessed January 15, 2013].

[29] J.D. Herbst, A.L. Gattozzi, A. Ouroua, F.M. Uriarte, "Flexible test bed for MVDC and HFAC electric ship power system architectures for navy ships,” Proc. IEEE Electric Ship Technologies Symp., pp. 6671, Alexandria, VA, USA, April 10-13, 2011.

[30] F. Katiraei and J. R. Aguero, "Solar PV Integration Challenges," Power \& Energy Magazine, pp. 62-71, May/June, 2011. 